REVIEW

\title{
Negro, Black, Black African, African Caribbean, African American or what? Labelling African origin populations in the health arena in the 21 st century
}

\author{
Charles Agyemang, Raj Bhopal, Marc Bruijnzeels
}

J Epidemiol Community Health 2005;59:1014-1018. doi: 10.1136/jech.2005.035964

Broad terms such as Black, African, or Black African are entrenched in scientific writings although there is considerable diversity within African descent populations and such terms may be both offensive and inaccurate. This paper outlines the heterogeneity within African populations, and discusses the strengths and limitations of the term Black and related labels from epidemiological and public health perspectives in Europe and the USA. This paper calls for debate on appropriate terminologies for African descent populations and concludes with the proposals that (1) describing the population under consideration is of paramount importance (2) the word African origin or simply African is an appropriate and necessary prefix for an ethnic label, for example, African Caribbean or African Kenyan or African Surinamese (3) documents should define the ethnic labels (4) the label Black should be phased out except when used in political contexts.

See end of article for authors' affiliations

.....................

Correspondence to: Dr C Agyemang, Department of Health Policy and Management, Erasmus Medical Center, Burg Oudlaan 50, L-gebouw, 3000 DR Rotterdam, Netherlands; C.Agyemang@ erasmusmc.nl

Accepted for publication 2 September 2005
$\mathrm{R}$ esearch on race, ethnicity, and health is growing in Western Europe, following the longer tradition in North America. The terms and concepts of ethnicity need to be explicitly defined to permit better understanding of research and to facilitate regional and international comparisons. ${ }^{12}$ Despite much debate, broad terms such as Black, African, or Black African are still entrenched in scientific writings that may be both offensive and inaccurate. This paper develops the debate called for by Bhopal in the Journal of Epidemiology and Community Health recently, and specifically tackles terminology in relation to African origin populations. This is also a companion paper to Bhopal and Donaldson's on the term White. ${ }^{3}$ Our general approach to terminology is described in the appendix. In this paper, we first briefly consider the concepts of race and ethnicity that underlie classifications and terminology. Then we outline the heterogeneity within African populations in Europe and the USA and then we discuss the terms used in medical and epidemiological research.

\section{RACE, ETHNICITY, AND HEALTH RESEARCH}

Both race and ethnicity are difficult concepts. ${ }^{4}$ While there is a conceptual distinction between race and ethnicity, these terms are often used interchangeably or as synonyms. The traditional scientific concept of race refers to biological homogeneity as defined by a few phenotypical features. ${ }^{1}$ Buffon first introduced the concept of race into biological literature in 1749 , which was explicitly regarded as an arbitrary classification, serving only as a convenient label and not a definable scientific entity. ${ }^{5}$ In the USA the collection of data on race is well established and is used widely for epidemiological, clinical, and planning purpose. ${ }^{6}$ However, the bulk of genetic differences (90\% to $95 \%$ ) occur within populations, and not between continental grouping, and the genes responsible for different physical characteristics (such as skin colour and facial features) that underpin race are few and rarely relate to either behaviour or disease. ${ }^{7-9}$ Current consensus is that race has comparatively little scientific value as there is more genetic variation within than between groups ${ }^{4}$ but that it is an important political and psychosocial concept. $^{10}$ The consensus about race is however, being revised because of genetic epidemiology, and particularly pharmacogenetics (so called ethno-pharmacology). ${ }^{11}$ The US Food and Drug Administration approval of BiDil, a new drug to treat heart failure in only African-American patients illustrate this point well. Many researchers and policy makers have long argued against the use of race categories in medicine as they reinforce existing social divisions in society or may lead to discriminatory practices. ${ }^{11}$

Ethnicity is a multidimensional concept, which is being used frequently in medical research. ${ }^{12}$ It is neither simple nor consistent. It comprises one or more of the following: shared origins or social background; shared culture or tradition that are distinctive, maintained between generations, and lead to a sense of identity and group; and a common language or religious tradition. ${ }^{1}$ The characteristics that define ethnicity are however, not fixed and may change over time, which makes ethnicity difficult to measure and use in research. ${ }^{12}$ The concept of ethnicity encapsulates cultural, behavioural, and environmental factors that increase the risk of disease; hence it is crucial in epidemiology and public health. In some parts of Europe, race is being abandoned in favour of ethnicity. ${ }^{913}$ The USA is moving to the compound phrase race/ethnicity. ${ }^{14}$ Also, in the USA race has been a proxy indicator for socioeconomic deprivation, which ignores for example, economically advantaged African Americans. Although social 
economic status is crucial in exploring ethnic disparity in health, it is inadequate to understand ethnic differences in health. ${ }^{75}$ The migration of socially deprived Eastern Europeans into Western Europe also shows that having European ancestry is no longer a homogenous description of persons of similar socioeconomic status. ${ }^{3}$

Self definition of ethnicity is currently gaining support. However, one of the main drawbacks of this approach is that people change their self assessment over time and with context, although this fluidity also has strengths. The current groupings of African descent populations in the USA and the UK such as Black, Black African, and African American hide the huge heterogeneity within these groups, which weakens the value of ethnic categorisation as a means of providing culturally appropriate health care, and in understanding the causes of ethnic differences in disease. Such broad terms may not fit with self definition of ethnicity.

Research on ethnicity and health has a scientific potential in determining the causes of disease, explaining the interaction between cultural factors and health, and ensuring that services and policies provide equitable access to health care. For example, why in comparison with the UK population as a whole, is hypertension so common in African Caribbeans ${ }^{16}$ but coronary heart disease is less common? ${ }^{17}$ The paradoxes behind many of the ethnic and racial differences in health are not easily explained, and better definitions and terminology, and greater attention to population heterogeneity are a prerequisite for scientific progress.

\section{HETEROGENEITY OF AFRICAN DESCENT POPULATIONS IN THE USA AND EUROPE}

The heterogeneity of African descent populations, ${ }^{78}$ South Asian, ${ }^{1}$ and White populations ${ }^{3}$ has long been pointed out.
After publications pointing out that the term "Asian" was an obstacle to ethnicity and health research, ${ }^{19}$ several gains have been made including the increasing division of South Asians groups into Indian, Pakistanis, and Bangladeshi in the UK national census in 1999 and 2001. A few journal editors have also set standards by publishing explicit guidelines for the use of race and ethnicity. ${ }^{20-22}$ Broader consensus is still needed in classifying African descent populations in Europe and the USA for epidemiological and public health research. Research on people originating from the African continent is of great interest in both Europe and the USA. African descent populations in Europe, as in the USA, are diverse but research into their health has yet to capture and capitalise on this. Ethnic classifications for African decent populations are often vaguely defined, and the concepts underlying them are poorly understood. ${ }^{8}$ Combining heterogeneous African populations under a single label such as Black creates practical problems of comparability between places and times, and reinforces the simplistic notion that being Black causes health disparity. ${ }^{23}$

There is considerable diversity within and between the African descent populations in Europe and those in the USA. The African descent populations in Europe came mainly from former colonies and from the West Indies in the 1950s and 1960s. ${ }^{18}{ }^{24}$ In the USA African descent populations include people from West Indies, Haiti, and various parts of Africa. ${ }^{25}$ These African descent groups are distinct in terms of beliefs, behaviours, risk factors, and factors such as height and weight and disease experience. ${ }^{26}{ }^{27}$ Several studies in the USA have shown considerable diversity in health status between different African populations. ${ }^{28-30}$ For example, Fang et al studied the association between birthplace and mortality from cardiovascular causes in New York City, USA and

Table 1 Analysis of terms currently in use to describe African origin populations

\begin{tabular}{|c|c|c|c|c|}
\hline Term & Meaning & Strengths & Weaknesses & Comments and recommendations \\
\hline $\begin{array}{l}\text { Negro (Negroid, } \\
\text { Homo Afer) }\end{array}$ & $\begin{array}{l}\text { People of black or dark } \\
\text { skinned race of mankind. }\end{array}$ & $\begin{array}{l}\text { Socially recognised and } \\
\text { historically lasting concept. }\end{array}$ & $\begin{array}{l}\text { Defined populations by physical } \\
\text { features in the distant past. } \\
\text { Used to describe heterogeneous } \\
\text { populations } \\
\text { Unrelated to ethnicity. } \\
\text { Considered offensive, associated with } \\
\text { slavery and contemptuous. }\end{array}$ & $\begin{array}{l}\text { Considered inappropriate and } \\
\text { derogatory. } \\
\text { Abandon in scientific writings. }\end{array}$ \\
\hline Black & As for Negro. & $\begin{array}{l}\text { Used in USA and UK censuses: } \\
\text { gives denominator; "usually } \\
\text { tested". } \\
\text { Socially recognised and } \\
\text { historically lasting concept. }\end{array}$ & $\begin{array}{l}\text { Used to describe heterogeneous } \\
\text { populations. Unrelated to ethnicity. }\end{array}$ & $\begin{array}{l}\text { In practice it refers to persons with sub- } \\
\text { Saharan African ancestral origins with } \\
\text { brown or black complexion. } \\
\text { In some circumstances the term Black } \\
\text { signifies all non-White minority } \\
\text { populations } \\
\text { Use with caution. }\end{array}$ \\
\hline African/origin & Applies to a native of Africa. & Signifies geographical origin. & $\begin{array}{l}\text { Geographically (continental) based. } \\
\text { Used to describe heterogeneous } \\
\text { populations. }\end{array}$ & $\begin{array}{l}\text { This term is currently the preferred prefix } \\
\text { for more specific categories, such as } \\
\text { African America, African Caribbean. } \\
\text { Using on its own should be avoided. }\end{array}$ \\
\hline Black African & $\begin{array}{l}\text { Refers to people, and their } \\
\text { offspring with African ancestral } \\
\text { origins who/family migrated } \\
\text { directly from sub-Saharan Africa. }\end{array}$ & $\begin{array}{l}\text { Used in UK censuses. } \\
\text { Signifies sub-continental origin. }\end{array}$ & $\begin{array}{l}\text { Very broad } \\
\text { Unrelated to ethnicity }\end{array}$ & Avoid if possible. \\
\hline $\begin{array}{l}\text { Afro-Caribbean/ } \\
\text { African Caribbean }\end{array}$ & $\begin{array}{l}\text { Applies to descents people, } \\
\text { and their offspring, with African } \\
\text { ancestral origin but migrated } \\
\text { via the Caribbean islands. }\end{array}$ & $\begin{array}{l}\text { Used in censuses } \\
\text { Signifies geographical origin } \\
\text { Attempts to describe a cultural } \\
\text { group }\end{array}$ & $\begin{array}{l}\text { Inaccurate unless it is a truly } \\
\text { representative population. } \\
\text { Used to describe heterogeneous } \\
\text { populations }\end{array}$ & $\begin{array}{l}\text { Useful and preferred if other ethnic } \\
\text { groups are not included. } \\
\text { Avoid combining other African groups. }\end{array}$ \\
\hline $\begin{array}{l}\text { Afro-American/ } \\
\text { African American }\end{array}$ & $\begin{array}{l}\text { Applies to people, and their } \\
\text { offspring, with African ancestral } \\
\text { origin (many are descendents } \\
\text { of persons brought as slaves). }\end{array}$ & $\begin{array}{l}\text { Used in USA censuses. } \\
\text { Signifies geographical origin. } \\
\text { Attempts to describe a cultural } \\
\text { group. } \\
\text { In practice, North Africans from } \\
\text { Algeria, Morocco and such } \\
\text { countries are excluded from this } \\
\text { category. }\end{array}$ & As for African Caribbean. & $\begin{array}{l}\text { Useful and preferred if other ethnic } \\
\text { groups are not included. }\end{array}$ \\
\hline
\end{tabular}


showed variations between American born Black people and Caribbean born Black people exceeding those between Black and White people. ${ }^{28}$ The UK data also show important differences among the African descent populations. ${ }^{17} 3132$ Taylor and colleagues found that the rate of ever smoking among urban, foreign born Black people was considerably lower compared with the US born Black people. ${ }^{33}$ In the UK, the prevalence of smoking was much higher in African Caribbeans compared with West Africans, ${ }^{34}$ a fact that is lost if they are lumped together as one homogenous group. Elam and colleagues' health survey among Black African people living in England showed a remarkable diversity within these groups including diet, religion, migration experience, and education, language, and health behaviours. ${ }^{24}$

\section{TERMINOLOGY}

Table 1 summarises the qualities of most of the terms used in the past few decades to describe African populations in race, ethnicity and health research. The dictionary derived meanings come mainly from the Compact Edition of Oxford English Dictionary, the Oxford Encyclopaedic English Dictionary, Oxford Reference English, and the New Lexicon Webster's Dictionary of the English Language.

\section{Negro}

The term Negro means the colour black in Spanish. The term Negro was widely used by White Europeans as a shortened form of the racial classification Negroid to describe people of sub-Saharan African heritage. Until the mid-20th century the term Negro was widely used for African Americans, but fell out of favour in the late 20th century. Today it is universally considered inappropriate and derogatory although it is used occasionally in some research reports. ${ }^{35}$ In its current use, the term is generally considered acceptable only when used by African origin people, in historical context, or in the name of organisations. The racial classification Negroid is also no longer widely accepted.

\section{Black}

The term Black generally refers to a person with African ancestral origins. In some circumstances, usually in politics or power struggles, the term Black signifies all non-White minority populations. The term Black has a long service in social, political, and everyday life and in its use to denote African ancestry is entrenched in epidemiological and public health language. ${ }^{14}$ While the term Black has a psychosocial and political significance, ${ }^{10}$ in epidemiology and public health, such a broad term is usually unhelpful. ${ }^{12}$ The term covers a wide range of ethnic and cultural backgrounds and is potentially offensive and unreliable. ${ }^{1}$ It conceals a remarkable heterogeneity of cultures among diverse African populations, and reinforces racial stereotypes. The continuing use of this broad term in epidemiology and public health may reflect pragmatic reasons such as small study numbers. However, the need for simplicity should be weighed against the dangers of stereotyping and incorrectness. The label may suffice for everyday conversation or political exchange but is too simple for scientific studies on causes of disease.

\section{African [origin]}

Ancient Romans used the name Africa terra- "land of the Afri" (or "Afer" singular) for the northern part of the continent, corresponding to modern day Tunisia. Today the name Africa is used to refer to the whole continent. The term African [origin] in the context of scientific writing on race and ethnicity usually refers to a person with African ancestral origins who self identifies or is identified by others as African, but usually excludes those residents of Africa of other ancestry, for example, Europeans and South Asians and sometimes excludes North Africans, for example, Algerians.
The term African without qualification categorises a population on an ill defined basis of a common continental and ancestral origin. This term, none the less, is currently the preferred prefix for more specific categories, such as African American and African Caribbean, which are based on territorial ethnic or cultural matters. The term African without such a qualification is too broad to have value in ethnicity and health research.

\section{Black African}

The term Black African, as usually used in the UK, refers to people and their offspring with African ancestral origins who migrated via sub-Saharan Africa. The term has a geographical meaning and a more general one. Some have challenged the appropriateness of the term Black African. For example, many Somali people in England felt that their culture has more in common with Arabic cultures and were more likely to mix with such groups rather than other African descent groups. ${ }^{24}$ In Scotland a re-appraisal of the census 1991 and 2001 questions is underway, in response to offence taken at the use of black in relation to Africans.

\section{African Caribbean /Afro-Caribbean}

The term African Caribbean /Afro-Caribbean when used in Europe and North America usually refers to people with African ancestral origins who migrated via the Caribbean islands. In the UK, this term is used inconsistently. Some researchers use it to refer to people who are Black and of Caribbean descent, ${ }^{36}{ }^{37}$ others to refer to people of either West African or Caribbean descent. ${ }^{34} 38{ }^{39}$ African Caribbean people have cultural values, which are different from other African populations in terms of language, diet, customs, beliefs, and migration history. ${ }^{24}$ These differences are recognised by the UK census ${ }^{40}$ and yet health researchers continue to combine these heterogeneous groups. The group African Caribbean is composed of people from a multitude of islands and the use of this term has been challenged. ${ }^{41}$ In addition, the health status among second and third generation of African Caribbeans is probably quite different from their parents or grandparents. Given the variations even within the African Caribbean community, lumping them together with African populations from Africa as one homogenous ethnic group, leads to differences between them being ignored.

\section{African American}

The term African American refers to a person of African ancestral origins who self identifies or is identified by others as African American. While the term African American has been used at least since the 1920s, it has been the preferred term in the USA since the 1970s. As most African Americans in the USA originated from sub-Saharan Africa, the term is not applied to Africans from northern African countries such as Morocco. Most African Americans are descendants of persons brought to the Americas as slaves between the 17th and 19th century (distant ancestry). Such people differ from others who came from Africa or the Caribbean in the 20th and 21 st centuries (recent ancestry), in terms of culture, language, migration history, and health. These differences are often ignored.

\section{MIXED ETHNICITY OR RACE}

The mixed ethnicity or race describes people whose ancestors are not of a single ethnicity or race. The importance of this category is being increasingly recognised as shown by the UK's 2001 census. In epidemiology and public health however, the categorisation of people with mixed ethnicity is still unclear and the current approaches are insufficient, partly because the number of potential categories is likely to be enormous. The emerging data suggest that health outcomes among people with mixed ethnicity differ from 
those without, which highlights the need for such a category in epidemiology and public health research. ${ }^{42}{ }^{43}$

\section{CONCLUSIONS AND RECOMMENDATIONS}

The division of South Asians groups into Indian, Pakistani, and Bangladeshi populations has helped to highlight the important differences in disease experiences among these ethnic groups in the UK. ${ }^{1}$ This implies that consensus on categorisation of diverse African descent populations could be achieved in both Europe and the USA in epidemiology and public health research. This also implies that researchers and professionals in the field of ethnicity and health should understand and acknowledge the massive diversity within the African descent populations and should avoid implying that they all share unique characteristics in common. Researchers in ethnicity and health should use the most specific term suitable to the purpose and the context of the study and avoid derogatory words. ${ }^{1}$ The essential starting point is a national, if not an international consensus among researchers in this field. This will require each country or region setting out explicitly their definitions and how they should be operationalised.

Descriptions of the population and these definitions should be given in documents. The term Negro/Negroid should be avoided in scientific writings because of its association with racism and race science. The word African or African origin is a suitable prefix for a more specific subpopulation, for example, African Kenyan or African Surinamese (hence different from Indian Kenyan or Hindustani Surinamese). With this approach the colour term Black can be phased out. In studies of racism, however, the term is central. The term African Caribbean needs to be defined and restricted to an African descent person originating from the Caribbean. Researchers could use more precise and descriptive terms such as first or second or third generation African Caribbeans. Alternatively, Caribbean born and UK born African Caribbean could also be usefully terms. The addition of country of birth to the data collection process might make the information more valuable. The term African American would be more useful if there was a description of what it means in the study, for example, African American of recent or distant ancestry from West Africa. Africans who are recent arrivals could be described by their specific origins, for example, American Caribbeans so restricting the label African American to those whose African ancestry is distant (three or more generations back).

The common practice of classifying people with mixed African descent and other ethnicity as Black or African Caribbean or African American needs to be reviewed. Without this, these populations will continue to remain hidden when policy on ethnic diversity is made.

Although not an automatic solution in classifying different African descent populations, the concept of ethnicity allows epidemiologists and public health researchers to break free from the concept of race, which carries historical taints of slavery, eugenics, Nazi race policy, and undue emphasis on biological heritage. Ethnicity provides a powerful alternative approach, which encapsulates within a broader framework the key facets of race. ${ }^{13}$

Despite these difficulties health research and scholarship on African origin populations, including better classifications needs to continue. There are important problems of excess disease and risks in some populations of African descent. They also have varying access and utilisation of health services, which cannot be uncovered and tackled properly if they are not studied, or the populations are lumped together as one homogeneous group.

Ethnicity and health researchers should move beyond the straightforward black/white category that was the dominant and limiting approach for most of the 20th century and access the considerable ethnic diversity that typify the population under study. ${ }^{26}$ Until more appropriate conceptualisation and definition of African descent populations is achieved internationally, much research on these ethnic groups will continue to remain controversial and often misleading. The resolution of the challenges identified here requires wider awareness and a greater involvement in generating solutions. This paper endorses, and contributes to the challenge identified in the Journal of Epidemiology and Community Health's glossary on ethnicity. ${ }^{13}$

\section{ACKNOWLEDGEMENTS}

We thank Dr Karien Stronks (Amsterdam Medical Centre) and Ank de Jonge (University Medical Centre, St Radboud, Nijmegen) and the REACH members (University of Rotterdam) for giving useful feedback on an earlier draft and Tori Hastie for her secretarial support. We are also indebted to the three referees who provided comments that helped to improve the earlier version of this paper.

\section{Authors' affiliations}

C Agyemang, M Bruijnzeels, Institute of Health Policy and Management, Erasmus Medical Centre, Rotterdam, Netherlands

R Bhopal, Public Health Sciences, Division of Community Health

Sciences, College of Medicine and Veterinary Medicine, University of Edinburgh, Edinburgh, UK

Funding: none.

Conflicts of interest: none declared.

\section{APPENDIX}

\section{POSTSCRIPT: A NOTE ON TERMINOLOGY RELATING TO ETHNICITY}

There is no consensus on appropriate terms for the scientific study of health by ethnicity, and published guidelines are yet to be widely adopted. We have followed general conventions used in the UK and, whenever appropriate, the terminology used in the original documents referred to. We have also followed principles in the glossary by Bhopal. ${ }^{13}$ For example, in the UK the term ethnic minority group usually refers to minority populations of non-European origin and characterised by their non-White status. (We use it this way here.) The terms relating to African origin populations are as discussed in this paper. In Europe, the term South Asian refers to populations originating from the Indian subcontinent, effectively, India, Pakistan, Bangladesh, and Sri Lanka. White is the term currently used to describe people with European ancestral origins. By ethnicity we mean the group a person belongs to as a result of a mix of cultural factors including language, diet, religion, and ancestry. We conceptualise race in its traditional way-that is, human subspecies-now largely discredited.

\section{REFERENCES}

1 Senior P, Bhopal R. Ethnicity as a variable in epidemiological research. BMJ 1994;309:327-9.

2 McKenzie K, Crowcroft NS. Describing race, ethnicity, and culture in medical research. BMJ 1996;312:1054.

3 Bhopal R, Donalson L. White, European, Western, Caucasian, or what? Inappropriate labelling of research on race, ethnicity and health. Am J Public Health 1998;88:1303-7.

4 Sheldon TA, Parker H. Race and ethnicity in health research. J Public Health Med 1992;14:104-10.

5 Montague A. The concept of race. Toronto: Collier-Macmillan, 1964.

6 Hahn RA. The state of federal health statistics on racial and ethnic groups. JAMA 1992;267:268-71

7 Cooper R, David R. The biological concept of race and its application to public health and epidemiology. J Health Politics Policy Law 1981;11:97-116.

8 Bhopal R. Is research into ethnicity and health racist, unsound, or important science? BMJ 1997;314:1751

9 Afshari R, Bhopal RS. Changing pattern of use of 'ethnicity' and 'race' in scientific literature. Int J Epidemiol 2002;31:1074. 
10 LaVeist TA. Beyond dummy variables and sample selection: what health services researchers ought to know about race as a variable. Health Serv Res 1994;29:1-16

11 Rahemtulla T, Bhopal R. Pharmacogenetics and ethnically targeted therapies. BMJ 2005;330:1036-7.

12 Mckenzie KJ, Crowcroft NS. Race, ethnicity, culture and science. BMJ 1994;309:286-7.

13 Bhopal R. Glossary of terms relating to ethnicity and race: for reflection and debate. J Epidemiol Community Health 2004;58:441-5.

14 Comstock RD, Castillo ED, Lindsay SP. Four-year review of the use of race and ethnicity in epidemiological and public health research. Am J Epidemiol 2004; 159:611-19.

15 Nazroo JY. Genetic, cultural or socio-economic vulnerability? Explaining inequalities in health. Sociology of Health and Illness 1998;20:710-30.

16 Agyemang C, Bhopal RS. Is the blood pressure of people from African origin adults in the UK higher or lower than that in European origin Whites? A review of cross-sectional data. J Hum Hypertens 2003; 17:523-34.

17 Balarajan R. Ethnic differences in mortality from ischaemic heart disease and cerebrovascular disease in England and Wales. BMJ 1991;302:560-4.

18 Cruickshanks JK, Beevers DG, eds. Ethnic factors in health and disease. London: Butterworths, 1989.

19 Bhopal RS, Phillimore P, Kohli HS. Inappropriate use of the term 'Asian': an obstacle to ethnicity and health research. J Public Health Med $1991 ; 13: 244-6$.

20 Anonymous. For discussion: race, ethnicity and nationality. Paediatr Perinat Epidemiol 2000;14:13.

21 Anonymous. Census, race and science. Nat Genet 2000;24:97-8.

22 Rivara FP, Finberg L. Use of term race and ethnicity. Arch Pediatr Adolesc Med 2001;155:119.

23 Kaplan JB, Benneth T. Use of race and ethnicity in biomedical publication. JAMA 2003;289:2709-16.

24 Elam G, McMunn A, Nazroo J. Feasibility study for Health Survey among black African people living in England, Final report for the Department of Health. London: Joint Health Surveys Unit and National Centre for Social Research, http://www.doh.gov.uk/pdfs/healthrptfeasibafricansurvey.pdf (accessed Sep 2004).

25 Williams DR, Jackson JS. Race/ethnicity and the 2000 census: recommendations for African American and other populations in the United States. Am J Public Health 2000;90:1728-30.

26 Williams DR. Race and health: basic questions, emerging directions. Ann Epidemiol 1997:7:322-33.

27 Oppenheimer GM. Paradigm lost: Race, ethnicity, and the search for new population taxonomy. Am J Public Health 2001;19:1049-55.
28 Fang J, Madhavan S, Alderman MH. The association between birthplace and mortality from cardiovascular causes among black and white residents of $\mathrm{New}$ York City. N Engl J Med 1996;335:1545-51.

29 Singh GK, Siahpush M. Ethnic-immigrant differentials in health behaviours, morbidity, and cause-specific mortality in the United States: an analysis of two national data bases. Hum Biol 2002;74:83-109.

30 David RJ, Collins JW. Differing birth weight among infants of US-born Blacks, African-Born Blacks, and US-born Whites. N Engl J Med 1997;337:1209-14.

31 Gill PS, Kai J, Bhopal RS, et al. Health care needs assessment: black and minority ethnic groups. In: Raftery J, ed. Health care needs assessment. The epidemiologically based needs assessment reviews. 3rd series. Abingdon Radcliffe Medical Press (in press). http://www.hcna.radcliffe-online.com/ bemgframe.htm

32 Low N, Sterne JAC, Barlow D. Inequalities in rates of gonorrhoea and chlamydia between black ethnic groups in south east London: cross sectional study. Sex Transm Infect 2001;77:15-20.

33 Taylor KL, Kerner JF, Gold KF, et al. Ever vs never smoking among an urban, multiethnic sample of Haitian, Caribbean, and US born black. Prev Med 1997;26:855-5.

34 Cappuccio FP, Cooj DG, Atkinson RW, et al. The Wandsworth heart and stroke study. A population-based survey of cardiovascular risk factors in different ethnic groups. Methods and baseline findings. Nutr Metab Cardiovasc Dis 1998;8:371-85.

35 Timmers GJ, Schouten JA, ter Wee PM, et al. [Hypertension in the Negro patient]. Ned Tijdschr Geneeskd 1999;143:229-34.

36 Cruickshank JK, Cooper J, Burnett M, et al. Ethnic differences in fasting plasma C-peptide and insulin in relation to glucose tolerance and blood pressure. Lancet 1991;338:842-7.

37 Karlsen S, Primatesta P, McMum A. Blood pressure. In: Erens B, Primatesta P, Prior $G$. Health survey for England-the health of minority ethnic groups ' 99 . London: Stationery Office, 2001:175-97.

38 Chaturvedi N, McKeigue PM, Marmot MG. Resting and ambulatory blood pressure; differences in Afro-Caribbeans and Europeans. Hypertension 1993;22:90-6.

39 Haines AP, Boorof A, Goldenberg E. Blood pressure, smoking, obesity and alcohol consumption in blacks and whites in general practice. J Hum Hypertens 1987;1:39-46.

40 Office of the National Statistics in the UK. Census 2001. http:// www.doh.gov.uk/ethdevlist3.htm (accessed 7 Sep 2004)

41 Rait G. Counting heads may mask cultural and social factors. BM 1999;318:305-6.

42 Collins JW Jr, David RJ. Race and birth weight in biracial infants. Am J Public Health 1993;83:1125-9.

43 Polednak AP, King G. Birth weight of US biracial (black-white) infants: regional differences. Ethn Dis 1998;8:340-9. 